\title{
The Effect of Students' Mathematics Self-efficacy on Mathematical Understanding Performance
}

\author{
Slamet Arifin, Universitas Kuningan, slamet.arifin@uniku.ac.id, ORCID: 0000-0001-6280-2592 \\ Wahyudin, Universitas Pendidikan Indonesia, wahyudin.mat@upi.edu, ORCID: 0000-0003-3930-1380 \\ Tatang Herman, Universitas Pendidikan Indonesia, tatangherman@upi.edu, ORCID: 0000-0002-4349- \\ 4042
}

\begin{abstract}
Numerous studies on students' attitude toward mathematics have suggested that a positive attitude predicts academic achievement. However, little research has been conducted in specific areas of academic achievement, such as mathematical understanding. Therefore, this study aimed to investigate the relationship between students' mathematics self-efficacy (SMSE) and students' mathematical understanding (SMU). The participants of this study were 4th-grade primary school students in Kuningan, Indonesia ( $\mathrm{N}=44)$. The data were collected through a questionnaire assessing students' mathematics self-efficacy (QSMSE) and a test of students' mathematical understanding (TSMU). First, the QSMSE was administered to the participants to measure SMSE. Then, the TSMU was applied to them to measure their SMU. The results indicate that SMSE is positively correlated with and has a significant effect on SMU. The results also reveal that students with a high level of SMSE perform better in their TSMU than students with medium and low SMSE. Furthermore, our findings indicate that SME could be the best predictor for student achievement, such as mathematical understanding.
\end{abstract}

Keywords: conceptual understanding, mathematical understanding, procedural fluency, mathematics self-efficacy

Received: 10.11 .2020

Accepted: 05.12.2020

Published: 05.01.2021

\section{INTRODUCTION}

Mathematical understanding is critical for supporting students' success in learning mathematics. According to the National Council of Teachers of Mathematics (NCTM; 2000), students must learn mathematics with understanding and actively build new knowledge through experience and prior knowledge. In this research, mathematical understanding is categorized into conceptual understanding and procedural fluency (Ben-hur, 2006; Schneider et al., 2011). Conceptual understanding refers to the understanding of mathematical concepts, operations, and relations. Procedural fluency is the skill of carrying out procedures flexibly, accurately, efficiently, and appropriately (National Research Council, 2001). Although cognitive dimensions such as conceptual understanding and procedural fluency are essential for students' success in mathematics (Cai \& Ding, 2015; Martin \& Towers, 2014), the affective dimension also plays an essential role as the cognitive dimension (NCTM, 2000). Therefore, the combination of both cognitive and affective dimensions has become an interesting issue for researchers in the area of mathematics education.

In recent decades, researchers in mathematics education have conducted studies investigating the relationship between students' attitude towards mathematics and achievement (Foster, 2016; Gao, 2020; Guven \& Cabakcor, 2013). Research evidence has shown that attitude towards mathematics has a positive correlation on a student's achievement in mathematics (Juter, 2005). Meta-analytic studies by Ma and Kishor (1997) indicated a positive correlation between attitude towards mathematics and performance in mathematics. Other evidence has proved that attitude towards mathematics strongly predicts success and persistence in the learning of mathematics (Singh et al., 2002). Furthermore, according to research conducted by Chen et al. (2018), a positive attitude towards mathematics may upregulate the brain systems involved in mnemonic processes in learning and memory formation, thereby facilitating knowledge acquisition and academic achievement.

Self-efficacy, a more specific area of attitude towards mathematics, has been determined as essential for an individual's academic success (Brown et al., 1989; Lent \& Brown, 1996). In the past few years, the relationship between a student's self-efficacy and their academic performance has been investigated by researchers in mathematics education since Bandura's conceptualization of self-efficacy 
(Komarraju \& Nadler, 2013; Yusuf, 2011). For instance, Roick and Ringeisen (2017) proved that students more control of their disposition set themselves higher target performances and beliefs to get better outcomes in mathematics. Self-efficacy refers to an individual's judgment about their capability to organize and execute a course of action to attain designated goals (Zimmerman \& Bandura, 1994). According to Klassen et al. (2010), self-efficacy is an individual's belief in their ability to enhance their performance through a range of mechanisms; an individual with a high level of self-efficacy sets more challenging goals, expends more effort, persists with challenges for longer, and shows resilience in the face of adversity. The social cognitive theory emphasizes that self-efficacy is an agentic motivational orientation that fuels persistence in the face of difficulties, increases intentionality and long-term planning, and promotes selfregulation and self-concerning actions (Bandura, 2001).

In the academic context, self-efficacy is often described as academic self-efficacy. Academic selfefficacy refers to individuals' convictions that they can successfully perform given academic tasks at designated levels (Schunk, 2012). In this research, we focused on mathematics self-efficacy as a particular area of academic self-efficacy. Researchers have operationalized mathematics self-efficacy as students' selfefficacy related to the learning area of mathematics (Toland \& Usher, 2016; Bone, 2016). Mathematics selfefficacy can be distinguished from other measures of attitudes toward mathematics. Mathematics selfefficacy is a situational or problem-specific assessment of an individual's confidence in her or his ability to successfully perform or accomplish a particular task or problem (Hackett \& Betz, 1989). Students' mathematics self-efficacy is essential because of its well-established association with achievement, which has been shown across a range of educational contexts.

Numerous evidence-based research studies have examined the link between self-efficacy and academic achievement (Drago et al., 2016; Chen et al., 2018; Dowker et al., 2019). However, only a few studies have been conducted in a specific area of academic achievement. Therefore, this study is focused on mathematical understanding as a particular area of students' achievement in mathematics. The purpose of this study is to contribute empirical evidence by examining the relationship between students' mathematical self-efficacy (SMSE) and students' mathematical understanding (SMU). In particular, the following two research questions were explored in our study:

1. Does students' mathematics self-efficacy (SMSE) have a positive correlation with students' mathematical understanding (SMU)?

2. Could students' mathematics self-efficacy (SMSE) be used as a predictor for students' mathematical understanding (SMU)?

\section{METHODOLOGY}

\section{Participants}

In total, 44 4th-grade primary school students were involved in this study. They were approximately between 10 and 11 years old, because, usually, students enter primary school at the age of 6 or 7. The participants were split into two different groups, with each group consisting of primary school students from Kuningan, Indonesia. Each group consisted of 22 students, as the typical primary school in Indonesia consists of between 20 and 30 students. The school which participated in this study is a public school located in the city center of the Kuningan district. In Indonesia the majority of schools are public, with the curriculum being defined on a national basis.

\section{Variables and Instruments}

The variables investigated in this study were SMSE and SMU, therefore, there are two types of instruments used in this study, including a questionnaire of student's mathematics self-efficacy (QSMSE) and a test of students' mathematical understanding (TSMU).

\section{Questionnaire of Student's Mathematics Self-efficacy}

The Questionnaire of Student's Mathematics Self-efficacy (QSMSE) was developed to measure student's mathematics self-efficacy. The QSMSE consists of 15 questions which have four scale answer responses. The questions were developed in accordance with several behavioral aspects that were evident in students who were affected by self-efficacy. According to social cognitive theorists, self-efficacy can affect several aspects of an individual's behavior, including choice of activity, goals, effort and persistence, as well as their learning and achievement (Bandura, 1997; Britner \& Pajares, 2006; Ormrod, 2016). That is why five types of criteria were used when developing the QSMSE. Moreover, the indicators used to develop the QSMSE are presented in Table 1 below.

Table 1. Indicator of Questionnaire of Student's Mathematics Self-efficacy (QSMSE) 


\begin{tabular}{|l|l|}
\hline \multicolumn{1}{|c|}{$\begin{array}{c}\text { The Aspect of Mathematics } \\
\text { Self-Efficacy }\end{array}$} & \multicolumn{1}{c|}{ Indicator } \\
\hline Beliefs & Student's beliefs of their mathematical ability \\
\hline Choice of action or activity & $\begin{array}{l}\text { Student's choice of action or activity when faced with mathematical } \\
\text { problems }\end{array}$ \\
\hline Goals & Student's goals when learning mathematics \\
\hline Effort & Student's effort when faced with mathematical problems \\
\hline Persistence & Student's persistence when faced with mathematical problems \\
\hline Interest & Student's interest when learning mathematics \\
\hline
\end{tabular}

\section{Test of Student's Mathematical Understanding}

The TSMU was used to assess students' mathematical understanding of the length and area of the square, rectangle and triangle. The test consists of 7 mathematical problems. The TSMU was developed to measure mathematical understanding in relation to students' conceptual understanding and procedural fluency (NCTM, 2000; NRC, 2001). Moreover, the indicators used to develop the test are presented in Table 2 below.

Table 2. Indicator of Test of Student's Mathematical Understanding (TSMU)

\begin{tabular}{|c|l|}
\hline $\begin{array}{c}\text { The Aspect of } \\
\text { Mathematical } \\
\text { Understanding }\end{array}$ & \\
\hline $\begin{array}{c}\text { Conceptual } \\
\text { understanding }\end{array}$ & Student's ability to build a relationship between mathematical concepts \\
\cline { 2 - 2 } & Student's ability to represent a mathematical situation in various situations \\
\cline { 2 - 2 } & Student's ability to use representation for a particular mathematics problem \\
\hline Procedural fluency & Students ability to implement mathematics procedures accurately \\
\cline { 2 - 2 } & $\begin{array}{l}\text { Student's ability to implement mathematical procedures in different contexts } \\
\text { or situations of mathematical problems }\end{array}$ \\
\cline { 2 - 2 } & Student's ability to modify procedures from other procedures \\
\cline { 2 - 2 } & $\begin{array}{l}\text { Student's ability to select and recognize which procedures are appropriate to } \\
\text { be implemented to solve mathematical problems }\end{array}$ \\
\hline
\end{tabular}

\section{Data Collection Procedure}

The data collection processes were divided into two phases during a week of mathematics lesson. The first phase was conducted before regular mathematics lessons of length and area of the square, rectangle, and triangle. The second phase was conducted at the end of regular mathematics lessons of length and area of the square, rectangle, and triangle. In particular, the data collection process is presented in figure 1.

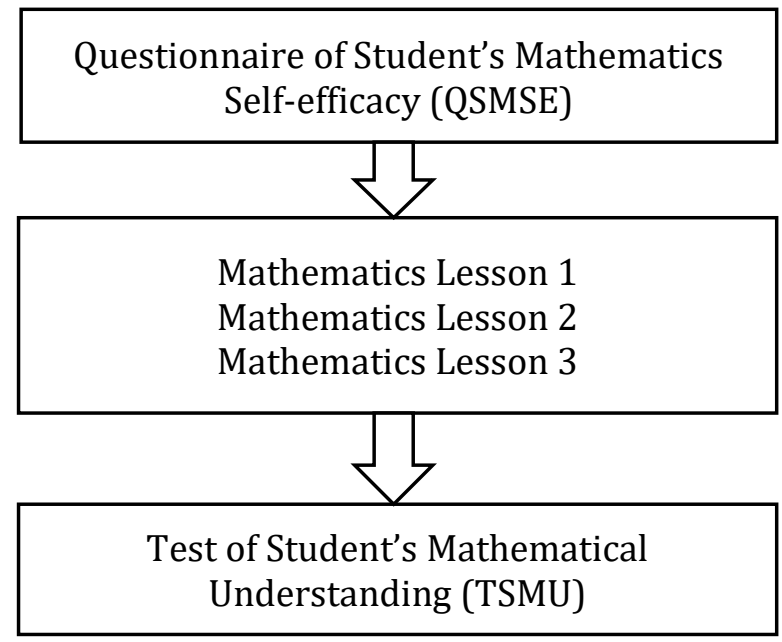

Figure 1. Data collection process

According to the data collection processes shown in Figure 1, there are two phases of the data collection processes. In the first phase, the QSMSE was administered to the participants to measure SMSE. The QSMSE was administered to each participant before they learn mathematics on a regular-basis about 
the area and length of square, rectangle, and triangle. The topic of length and area of the square, rectangle, and triangle were taught in three sessions of mathematics lessons, and each season was conducted in 105 minutes. In the second session, TSMU was applied to the participants in order to collect the data about students' mathematical understanding (SMU). The TSMU was administered to assess students' mathematical understanding of the area and length of square, rectangle, and triangle.

\section{Data Analysis}

Several data analyses were conducted to address the objective of this study. For the quantitative study, the data were analyzed statistically using statistical software IBM SPSS 20 . Figure 2 shows the steps involved in the data analysis process.

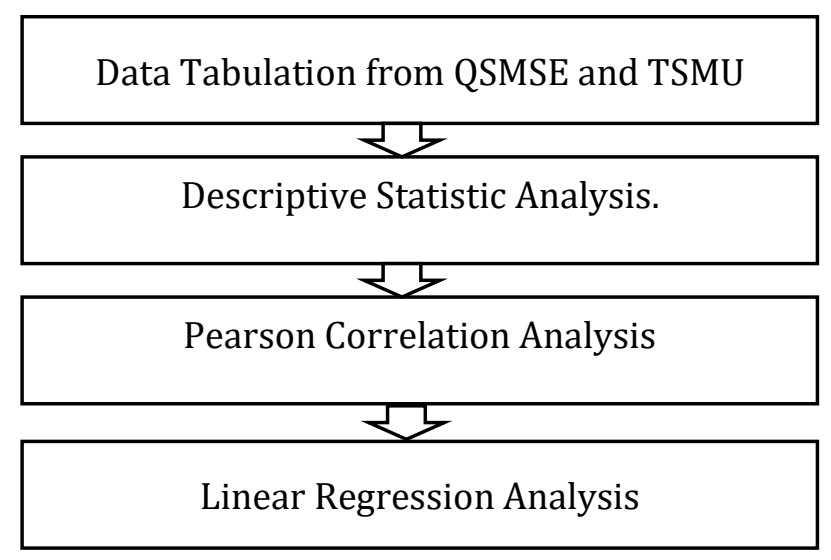

Figure 2. Data Analysis Process

According to Figure 2, there are four main stages of the data analysis process. In the first stage, all the data collected from QSMSE and SMU were tabulated. In the second stage, these data were analyzed using descriptive statistical analysis. The descriptive analysis test was conducted to measure mean, standard deviation, and normality. Moreover, in a particular condition, the data about SMSE were analyzed to classify the students into three levels of SMSE: low, medium, and high. The criteria-based standard score used to categorize students' level of mathematics self-efficacy is presented in Table 3.

Table 3. The Standard Criteria of SMSE-Level Classification

\begin{tabular}{|c|c|}
\hline Score Range & Categories \\
\hline $46-60$ & High \\
\hline $31-45$ & Medium \\
\hline $15-30$ & Low \\
\hline
\end{tabular}

The third stage of the data analysis was conducted to address the first research question. In this stage, the data were analyzed using the Pearson Correlation test to investigate the relationship between SMSU and SMU. In the last stage, the regression analysis was used to investigate whether SMSE could predict SMU. In this stage, a post-hoc analysis was also conducted to compare the mean differences of SMU based on the categorization of SMSE.

\section{RESULTS}

\section{Descriptive Analysis}

We started by conducting descriptive statistics analysis from both variables. In the initial process, we categorized students into groups based on three levels, namely low, medium, and high levels of students' mathematics self-efficacy (SMSE). The results of the categorization of students, based in particular on the level of SMSE, are presented in Figure 3. 


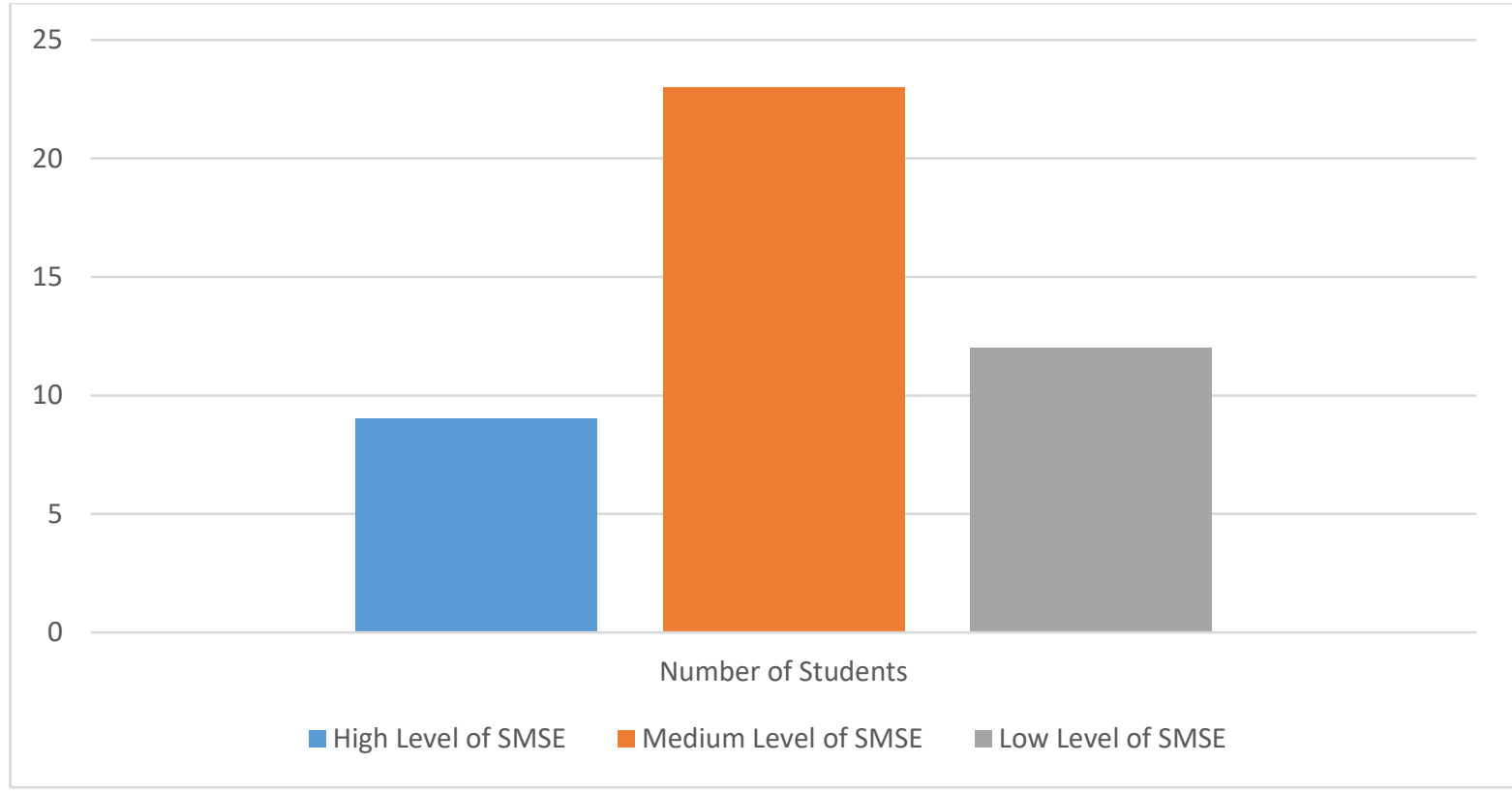

Figure 3. Number of Students based on the SMSE level

The data presented in figure three shows that most of the students have a medium level of SMSE. There are 12 students with a low level of SMSE (nine males and three females). The group of students with a high level of SMSE consists of nine students (six females and three males). As we mentioned earlier, most of the students have a medium level of SMSE. The medium level group consists of 23 students ( 13 females and 10 males).

Table 4. Descriptive Statistic of SMSE and SMU

\begin{tabular}{|l|c|c|c|}
\hline \multicolumn{1}{|c|}{ Aspect Measured } & M & SD & N \\
\hline $\begin{array}{l}\text { Students' mathematics self- } \\
\text { efficacy (SMSE) }\end{array}$ & 37.59 & 8.32 & 44 \\
\hline $\begin{array}{l}\text { Students' mathematical } \\
\text { understanding (SMU) }\end{array}$ & 65.59 & 17.02 & 44 \\
\hline
\end{tabular}

N: Number of Students

According to the data shown in Table 4, the results of the descriptive analysis indicate that the mean $(M)$ of SMSE is 37.59. The score range of SMSE is between the minimum score $(M i n=15)$ and the maximum score $(M a x=60)$. The standard deviation (SD) of SMSE is 8.32. Furthermore, the analysis of results of SMU presented in Table 4 shows the mean of SMU $(M=65.59)$ from the score range between the minimum score $(M i n=0)$ and the maximum score $(\operatorname{Max}=100)$.

Table 5. The Kolmogorov-Smirnov Normality Test

\begin{tabular}{|l|c|c|c|}
\hline & Statistic & df & Sig. \\
\hline SMSE & .122 & 44 & .101 \\
\hline SMU & .131 & 44 & .056 \\
\hline
\end{tabular}

The results of the normality test indicate that the data related to SMSE and SMU are normal. As presented in Table 4, the value of SMSE ( $p=0.101>\alpha=0.05)$ and SMU $(p=0.056>\alpha=0.05)$ indicates that both sets of data are normal at the 0.05 level.

\section{Relationship between SMSE and SMU}

To address the first research question, a correlational analysis was conducted by using the Pearson Correlation Test to investigate the correlation between SMSE and SMU. In particular, the results of the Pearson Correlation Test are presented in Table 6. 
Table 6. Pearson Correlation Test

\begin{tabular}{|c|c|c|c|}
\hline & & SMSE & SMU \\
\hline \multirow[t]{3}{*}{ SMSE } & Pearson Correlation & 1 & $.789 * *$ \\
\hline & Sig. (2-tailed) & & .000 \\
\hline & $\mathrm{N}$ & 44 & 44 \\
\hline \multirow[t]{3}{*}{ SMU } & Pearson Correlation & $.789 * *$ & 1 \\
\hline & Sig. (2-tailed) & .000 & \\
\hline & $\mathrm{N}$ & 44 & 44 \\
\hline
\end{tabular}

The data shown in Table 6 indicates $r(44)=789, p<0.01$. Therefore, we can conclude that there is a positive correlation between SMSE and SMU.

\section{The Predictive Power of SMSE and SMU}

The second research question addressed in this research was whether SMSE could predict SMU. To address this research question, linear regression analysis was conducted. Moreover, the results of the analysis are presented in Table 7.

Table 7. Regression Analysis

\begin{tabular}{|l|c|c|c|c|c|}
\hline Variables & B & SE & $\boldsymbol{\beta}$ & t & P \\
\hline Constant & 4.974 & 7.458 & & .667 & .508 \\
\hline SMSE & 1.613 & .194 & .789 & 8.321 & .000 \\
\hline
\end{tabular}

The data presented in Table 7 shows that the results of the regression analysis indicate that the predictor variable explained $62 \%$ of the variance $\left(R^{2}=.789, \mathrm{~F}[1,42]=2.971, p<0.001\right)$. This indicates that SMSE could significantly predict SMU. In order to strengthen our findings, then the mean comparison was conducted to measure whether the mean comparisons of SMU are significantly different from each group level of SMSE.

\section{Comparison of SMU based on Level of SMSE}

The post-hoc test was conducted to compare the mean of SMU based on the category low, medium, and high-level of SMSE. In particular, the result of post hoc analysis, in particular, is presented in Table 8.

Table 8. Post Hoc Test

\begin{tabular}{|l|l|l|r|r|c|}
\hline & \multirow{2}{*}{ (I) Level } & (J) Level & $\begin{array}{c}\text { Mean } \\
\text { Difference (I- } \\
\text { J) }\end{array}$ & Std. Error & Sig. \\
\hline \multirow{5}{*}{ Tukey HSD } & \multirow{2}{*}{ Low MSE } & Medium MSE & $-14.84420^{*}$ & 4.19782 & .003 \\
\cline { 2 - 6 } & Medium & Low MSE & $-36.25000^{*}$ & 5.19807 & .000 \\
\cline { 2 - 6 } & MSE & High MSE & $-21.44420^{*}$ & 4.19782 & .003 \\
\cline { 2 - 6 } & \multirow{2}{*}{ High MSE } & Low MSE & $36.25000^{*}$ & 4.63484 & .000 \\
\cline { 3 - 6 } & Medium MSE & $21.40580^{*}$ & 4.63484 & .000 \\
\hline
\end{tabular}

*. The mean difference is significant at the 0.05 level

The post-hoc test result presented in Table 8 indicates that each level of SMSE produces different scores of their SMU. Students with high-level of SMSE perform higher achievement on their TSMU than the medium and low level of SMSE. Students with the medium-level of SMSE perform lower achievement on SMU than students with high-level of SMSE and higher than students with low-level of SMSE. Moreover, students with low-level of SMSE perform the lowest achievement on SMU comparing with students with high and medium-level of SMSE. 


\section{DISCUSSION and CONCLUSIONS}

\section{Discussion}

The main aim of this study was to investigate the relationship between students' mathematics self-efficacy (SMSE) and students' mathematical understanding (SMU). The result of the correlation analysis indicates that SMSE scores were positively correlated with SMU. Our findings were consistent with evidence from previous research that concludes that self-efficacy has a positive and significant correlation with a student's achievement (Ayotola \& Adedeji, 2009; Hoffman \& Schraw, 2009; Honicke \& Broadbent, 2016; Stevens et al., 2016). For instance, research conducted by Honicke and Broadbent (2016) proved that academic selfefficacy moderately correlated with academic performance. Furthermore, Stevens et al. (2016) proved that there is a strong relationship between prior mathematics achievement and self-efficacy. Our findings are also consistent with research conducted by Cheema (2017) that proved that, in one particular area of mathematics self-efficacy and achievement, math self-efficacy is strongly associated with math literacy. Furthermore, Bone (2017) stated that a student's mathematics self-efficacy is likely to affect their mathematics achievement.

Our research findings also reveal that students' mathematical understanding was strongly predicted by student's mathematical self-efficacy. Students with high mathematics self-efficacy also had high mathematical understanding. On the other hand, students with low mathematics self-efficacy also performed more poorly on their mathematical understanding test. According to Bandura's (1977) Social Cognitive Theory, self-efficacy can play an essential role in determining individual perceptions and approaches to various tasks and goals. Individuals with high levels of self-efficacy approach problems as tasks that must be mastered while those with lower self-efficacy see them as hurdles to be avoided (Bandura, 1997).

Students with high mathematics self-efficacy solve mathematics problems more accurately and efficiently than students with low mathematics self-efficacy. In accordance with our findings, Komarraju and Nadler (2013) reported that students who are more confident and self-assured are more likely to report high levels of academic performance. Moreover, Gregory et al. (2019) concluded that improvement of mathematics self-efficacy was associated with students' successful performance in the numeracy test. Students' mathematics self-efficacy predicts their achievement or grades (Skaalvik et al., 2015). This is also in accordance with research by Ferla et al. (2009), which concluded that academic self-efficacy is the best predictor (and mediator) of academic achievement.

As stated by Greene et al. (2004), a student's confidence in their ability to be successful in the classroom is essential. Teachers need to develop and monitor students' mathematics self-efficacy during the mathematics learning process by providing strategies that create a positive climate in teaching and learning mathematics (Greensfeld \& Deutsch, 2020). Therefore, teacher attention toward the affective dimension in mathematics teaching and learning practice is important to support students' success in math.

\section{Conclusion}

Considering that the development of students' mathematics proficiency is not only focused on the cognitive domain but also the affective, understanding the relationship between the two domains is essential. Therefore, to confirm the relationship between the two domains, our research focuses on examining the relationship of students' mathematics self-efficacy (SMSE) with students' mathematical understanding (SMU). Based on our study, two main findings could be extended to support previous research that focused on attitude toward mathematics in general and particularly on the relationship between mathematics selfefficacy and academic performance. Our findings prove that students' mathematics self-efficacy (SMSE) is positively correlated with students' mathematical understanding (SMU). Furthermore, our results reveal that differing levels of mathematics self-efficacy lead to different performance in mathematical understanding. Students with high level of mathematics self-efficacy achieve higher score on their mathematical understanding test than students with medium and low level of mathematics self-efficacy. Therefore, the last finding concludes that mathematics self-efficacy could be the best predictor for student's mathematics achievement, particularly as conducted in this study, which is the student's mathematical understanding.

\section{Limitation and Future Direction}

It is necessary to acknowledge the limitations of this research that could influence further research and practice. An important limitation relates to the recruited sample of 4th grade students, which means that the findings may not be generalizable outside of the primary school context. Furthermore, since students in earlier grades are at different stages of development compared to the research participants, it is possible that the research findings may not be reproduced if a different population is considered. Another limitation 
relates to mathematical proficiency. In this research, we viewed mathematical understanding as an element of mathematical proficiency that ought to be developed for mathematics students. It would be worthwhile for future researchers to address these limitations, for example, by examining mathematical reasoning, problem-solving, and other more specific dimensions of mathematical proficiency. This study's findings have implications for schools and mathematics teachers, particularly in the areas of mathematics selfefficacy and mathematical understanding. The findings indicate that improving self-efficacy in students should be a core element of supporting students to gain proficiency in mathematics learning.

\section{REFERENCES}

Ayotola, A., \& Adedeji, T. (2009). The relationship between mathematics self-efficacy and achievement in mathematics. Procedia - Social and Behavioral Sciences, 1(1), 953-957. https://doi.org/10.1016/j.sbspro.2009.01.169

Bandura, A. (1977). Social Learning Theory. New Jersey: Prenticee-Hall, Inc.

Bandura, A. (1997). Self-Efficacy: The Exercise of Control. New York: W. H. Freeman \& Co.

Bandura, A. (2001). Social cognitive theory : An agentic perspective. Annual Review Psychology, 52, 1-26.

Ben-hur, M. (2006). Mathematics Instruction Mathematics Instruction. Alexandria: ASCD.

Bone, L., \& Lawes, E. (2016). Assessing students ' maths self-efficacy and achievement. Set, 2, 60-63. https://doi.org/10.18296/set.0048

Britner, S. L., \& Pajares, F. (2006). Sources of Science Self-Efficacy Beliefs of Middle School Students. Journal of Research in Science Teaching, 43(5), 485-499. https://doi.org/10.1002/tea.20131

Brown, S. D., Lent, R. W., \& Larkin, K. C. (1989). Self-Efficacy as a Moderator of Scholastic Aptitude-Academic Performance Relationships. 75, 64-75.

Cai, J., \& Ding, M. (2015). On mathematical understanding: perspectives of experienced Chinese mathematics teachers. Journal of Mathematics Teacher Education. https://doi.org/10.1007/s10857$015-9325-8$

Cheema, J. R. (2017). Effect of math-specific self-efficacy on math literacy: Evidence from a Greek survey. Research in Education, (1988), 1-24. https://doi.org/10.1177/0034523717741914

Chen, L., Bae, S. R., Battista, C., Qin, S., Chen, T., Evans, T. M., \& Menon, V. (2018a). Positive Attitude Toward Math Supports Early Academic Success: Behavioral Evidence and Neurocognitive Mechanisms. Psychological Science, 1-13. https://doi.org/10.1177/0956797617735528

Dowker, A., Cheriton, O., Horton, R., \& Mark, W. (2019). Relationships between attitudes and performance in young children' s mathematics. Educationl Studies in Mathematics, 100, 211-230.

Drago, A., Rheinheimer, D. C., \& Detweiler, T. N. (2016). Effects of Locus of Control , Academic Tutoring on Academic Performance. Journal of College Student Retention: Research, Theory \& Practice, 0(0), 1-19. https://doi.org/10.1177/1521025116645602

Ferla, J., Valcke, M., \& Cai, Y. (2009). Academic self-ef fi cacy and academic self-concept: Reconsidering structural relationships. Learning and Individual Differences, 19(4), 499-505. https://doi.org/10.1016/j.lindif.2009.05.004

Foster, C. (2016). Confidence and competence with mathematical procedures. Educational Studies in Mathematics, 91(December 2015), 271-288. https://doi.org/10.1007/s10649-015-9660-9

Gao, J. (2020). Sources of Mathematics Self-Efficacy in Chinese Students: a Mixed-Method Study with QSorting Procedure. International Journal of Science and Mathematics Education, 18(4), 713-732. https://doi.org/10.1007/s10763-019-09984-1

Greene, B. A., Miller, R. B., Crowson, H. M., Duke, B. L., \& Akey, K. L. (2004). Predicting high school students Õ cognitive engagement and achievement: Contributions of classroom perceptions and motivation q. $\begin{array}{llll}\text { Contemporary } & \text { Educational } & \text { Psychology, } & 29,\end{array}$ https://doi.org/10.1016/j.cedpsych.2004.01.006

Greensfeld, H., \& Deutsch, Z. (2020). Mathematical challenges and the positive emotions they engender. Mathematics Education Research Journal. https://doi.org/10.1007/s13394-020-00330-1

Gregory, L., Villarosa, A. R., Ramjan, L. M., Hughes, M., O’Reilly, R., Stunden, A., ... Salamonson, Y. (2019). The influence of mathematics self-efficacy on numeracy performance in first-year nursing students: A quasi-experimental study. Journal of Clinical Nursing, 28(19-20), 3651-3659. https://doi.org/10.1111/jocn.14963

Guven, B., \& Cabakcor, B. O. (2013). Factors influencing mathematical problem-solving achievement of seventh grade Turkish students. Learning and Individual Differences, 23(1), 131-137. https://doi.org/10.1016/j.lindif.2012.10.003

Hackett, G., \& Betz, N. E. (1989). An Exploration of the Mathematics Self-Efficacy/Mathematics Performance Correspondence. Journal for Research in Mathematics Education, 20(3), 261. 
https://doi.org/10.2307/749515

Hoffman, B., \& Schraw, G. (2009). The influence of self-ef fi cacy and working memory capacity on problemsolving ef $\mathrm{fi}$ ciency. Learning and Individual Differences, 19, 91-100. https://doi.org/10.1016/j.lindif.2008.08.001

Honicke, T., \& Broadbent, J. (2016). The in fl uence of academic self-ef fi cacy on academic performance : A systematic review. Educational Research Review, 17, 63-84. https://doi.org/10.1016/j.edurev.2015.11.002

Juter, K. (2005). Students' attitudes to mathematics and performance in limits of functions. Mathematics Education Research Journal, 17(2), 91-110. https://doi.org/10.1007/BF03217417

Klassen, R. M., Usher, E. L., Wigfield, A., Cambria, J., Vansteenkiste, M., Niemiec, C. P., \& Soenens, B. (2010). The Decade Ahead : Theoretical Perspectives on Motivation and Achievement Article information : In The Decade Ahead: Theoretical Perspectives on Motivation and Achievement, 16A, 1-33.

Komarraju, M., \& Nadler, D. (2013). Self-ef fi cacy and academic achievement : Why do implicit beliefs, goals , and effort regulation matter? Learning and Individual Differences, 25, 67-72. https://doi.org/10.1016/j.lindif.2013.01.005

Lent, R. W., \& Brown, S. D. (1996). Cognitive Assessment of the Sources Mathematics Self-Efficacy: A Thought-Listing Analysis. Journal of Career Assessment, 4(August), 33-46.

Ma, X., \& Kishor, N. (1997). Attitude Toward Self, Social Factors, and Achievement in Mathematics. Educational Psychology Review, 9(2), 89-120. Retrieved from https://link.springer.com/article/10.1023/A\%3A1024785812050

Martin, L. C., \& Towers, J. (2014). Growing mathematical understanding through Collective Image Making , Collective Image Having, and Collective Property Noticing. Educational Studies in Mathematics. https://doi.org/10.1007/s10649-014-9552-4

National Research Council. (2001). Adding it Up (J. Kilpatrick, J. Swafford, \& B. Findell, eds.). Washington: National Academic Press.

NCTM. (2000). Principles and Standards for School Mathematics. Reston, VA: The National Council of Teachers of Mathematics.

Ormrod, J. E. (2016). Human learning (7th Editio). Boston: Pearson Education, Inc.

Roick, J., \& Ringeisen, T. (2017). Self-efficacy, test anxiety, and academic success: A longitudinal validation. International Journal of Educational Research, 83, 84-93. https://doi.org/10.1016/j.ijer.2016.12.006

Schneider, M., Rittle-Johnson, B., \& Star, J. R. (2011). Relations among conceptual knowledge, procedural knowledge, and procedural flexibility in two samples differing in prior knowledge. Developmental Psychology, 47(6), 1525-1538. https://doi.org/10.1037/a0024997

Schunk, D. H. (2012). Learning theories. In Printice Hall Inc., New Jersey. https://doi.org/10.1017/CB09781107415324.004

Singh, K., Granville, M., \& Dika, S. (2002). Mathematics and science achievement: Effects of motivation, interest, and academic engagement. Journal of Educational Research, 95(6), 323-332. https://doi.org/10.1080/00220670209596607

Skaalvik, E. M., Federici, R. A., \& Klassen, R. M. (2015). Mathematics achievement and self-efficacy: Relations with motivation for mathematics. International Journal of Educational Research, 72, 129-136. https://doi.org/10.1016/j.ijer.2015.06.008

Stevens, T., Jr, A. O., Lan, W. Y., Tallent-runnels, M. K., Stevens, T., Tallent-runnels, M. K., \& Olivarez, A. (2016). Role of Mathematics Self-Efficacy and Motivation in Mathematics Performance Across Ethnicity. 97(4), 208-221.

Toland, M. D., \& Usher, E. L. (2016). Assessing Mathematics Self-Efficacy: How Many Categories Do We Really. Journal of Early Adolescence, 36(7), 932-960. https://doi.org/10.1177/0272431615588952

Yusuf, M. (2011). The impact of self-efficacy, achievement motivation, and self-regulated learning strategies on students' academic achievement. Procedia - Social and Behavioral Sciences, 15, 2623-2626. https://doi.org/10.1016/j.sbspro.2011.04.158

Zimmerman, B. J., \& Bandura, A. (1994). Impact of Self-Regulatory Influence on Writing Course Attainment. American Educational Research Journal, 31(4), 845-862. https://doi.org/10.3102/00028312031004845

Britner, S. L., \& Pajares, F. (2006). Sources of Science Self-Efficacy Beliefs of Middle School Students. Journal of Research in Science Teaching, 43(5), 485-499. https://doi.org/10.1002/tea.20131

Brown, S. D., Lent, R. W., \& Larkin, K. C. (1989). Self-Efficacy as a Moderator of Scholastic Aptitude-Academic Performance Relationships. 75, 64-75.

Cai, J., \& Ding, M. (2015). On mathematical understanding: perspectives of experienced Chinese mathematics teachers. Journal of Mathematics Teacher Education. https://doi.org/10.1007/s10857015-9325-8 
Cheema, J. R. (2017). Effect of math-specific self-efficacy on math literacy : Evidence from a Greek survey. Research in Education, (1988), 1-24. https://doi.org/10.1177/0034523717741914

Chen, L., Bae, S. R., Battista, C., Qin, S., Chen, T., Evans, T. M., \& Menon, V. (2018). Positive Attitude Toward Math Supports Early Academic Success: Behavioral Evidence and Neurocognitive Mechanisms. Psychological Science, 1-13. https://doi.org/10.1177/0956797617735528

Dowker, A., Cheriton, O., Horton, R., \& Mark, W. (2019). Relationships between attitudes and performance in young children' s mathematics. Educationl Studies in Mathematics, 100, 211-230.

Drago, A., Rheinheimer, D. C., \& Detweiler, T. N. (2016). Effects of Locus of Control , Academic Tutoring on Academic Performance. Journal of College Student Retention: Research, Theory \& Practice, 0(0), 1-19. https://doi.org/10.1177/1521025116645602

Ferla, J., Valcke, M., \& Cai, Y. (2009). Academic self-ef fi cacy and academic self-concept: Reconsidering structural relationships. Learning and Individual Differences, 19(4), 499-505. https://doi.org/10.1016/j.lindif.2009.05.004

Foster, C. (2016). Confidence and competence with mathematical procedures. Educational Studies in Mathematics, 91(December 2015), 271-288. https://doi.org/10.1007/s10649-015-9660-9

Gao, J. (2020). Sources of Mathematics Self-Efficacy in Chinese Students: a Mixed-Method Study with QSorting Procedure. International Journal of Science and Mathematics Education, 18(4), 713-732. https://doi.org/10.1007/s10763-019-09984-1

Greene, B. A., Miller, R. B., Crowson, H. M., Duke, B. L., \& Akey, K. L. (2004). Predicting high school students Õ cognitive engagement and achievement: Contributions of classroom perceptions and motivation $\mathrm{q}$.

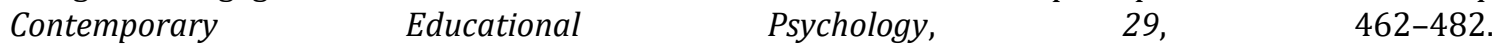
https://doi.org/10.1016/j.cedpsych.2004.01.006

Greensfeld, H., \& Deutsch, Z. (2020). Mathematical challenges and the positive emotions they engender. Mathematics Education Research Journal. https://doi.org/10.1007/s13394-020-00330-1

Gregory, L., Villarosa, A. R., Ramjan, L. M., Hughes, M., O'Reilly, R., Stunden, A., ... Salamonson, Y. (2019). The influence of mathematics self-efficacy on numeracy performance in first-year nursing students: A quasi-experimental study. Journal of Clinical Nursing, 28(19-20), 3651-3659. https://doi.org/10.1111/jocn.14963

Guven, B., \& Cabakcor, B. O. (2013). Factors influencing mathematical problem-solving achievement of seventh grade Turkish students. Learning and Individual Differences, 23(1), 131-137. https://doi.org/10.1016/j.lindif.2012.10.003

Hackett, G., \& Betz, N. E. (1989). An Exploration of the Mathematics Self-Efficacy/Mathematics Performance Correspondence. Journal for Research in Mathematics Education, 20(3), 261. https://doi.org/10.2307/749515

Hoffman, B., \& Schraw, G. (2009). The influence of self-efficacy and working memory capacity on problemsolving efficiency. Learning and Individual Differences, 19, 91-100. https://doi.org/10.1016/j.lindif.2008.08.001

Honicke, T., \& Broadbent, J. (2016). The in fl uence of academic self-efficacy on academic performance : A systematic review. Educational Research Review, 17, 63-84. https://doi.org/10.1016/j.edurev.2015.11.002

Juter, K. (2005). Students' attitudes to mathematics and performance in limits of functions. Mathematics Education Research Journal, 17(2), 91-110. https://doi.org/10.1007/BF03217417

Klassen, R. M., Usher, E. L., Wigfield, A., Cambria, J., Vansteenkiste, M., Niemiec, C. P., \& Soenens, B. (2010). The Decade Ahead : Theoretical Perspectives on Motivation and Achievement Article information: In The Decade Ahead: Theoretical Perspectives on Motivation and Achievement, 16A, 1-33.

Komarraju, M., \& Nadler, D. (2013). Self-ef fi cacy and academic achievement : Why do implicit beliefs, goals , and effort regulation matter? Learning and Individual Differences, 25, 67-72. https://doi.org/10.1016/j.lindif.2013.01.005

Lent, R. W., \& Brown, S. D. (1996). Cognitive Assessment of the Sources Mathematics Self-Efficacy: A Thought-Listing Analysis. Journal of Career Assessment, 4(August), 33-46.

Ma, X., \& Kishor, N. (1997). Attitude Toward Self, Social Factors, and Achievement in Mathematics. Educational Psychology Review, 9(2), 89-120. Retrieved from https://link.springer.com/article/10.1023/A\%3A1024785812050

Martin, L. C., \& Towers, J. (2014). Growing mathematical understanding through Collective Image Making, Collective Image Having, and Collective Property Noticing. Educational Studies in Mathematics. https://doi.org/10.1007/s10649-014-9552-4

National Research Council. (2001). Adding it Up (J. Kilpatrick, J. Swafford, \& B. Findell, eds.). Washington: National Academic Press.

NCTM. (2000). Principles and Standards for School Mathematics. Reston, VA: The National Council of 
Teachers of Mathematics.

Ormrod, J. E. (2016). Human learning (7th Editio). Boston: Pearson Education, Inc.

Roick, J., \& Ringeisen, T. (2017). Self-efficacy, test anxiety, and academic success: A longitudinal validation. International Journal of Educational Research, 83, 84-93. https://doi.org/10.1016/j.ijer.2016.12.006

Schneider, M., Rittle-Johnson, B., \& Star, J. R. (2011). Relations among conceptual knowledge, procedural knowledge, and procedural flexibility in two samples differing in prior knowledge. Developmental Psychology, 47(6), 1525-1538. https://doi.org/10.1037/a0024997

Schunk, D. H. (2012). Learning theories. In Printice Hall Inc., New Jersey. https://doi.org/10.1017/CB09781107415324.004

Singh, K., Granville, M., \& Dika, S. (2002). Mathematics and science achievement: Effects of motivation, interest, and academic engagement. Journal of Educational Research, 95(6), 323-332. https://doi.org/10.1080/00220670209596607

Skaalvik, E. M., Federici, R. A., \& Klassen, R. M. (2015). Mathematics achievement and self-efficacy: Relations with motivation for mathematics. International Journal of Educational Research, 72, 129-136. https://doi.org/10.1016/j.ijer.2015.06.008

Stevens, T., Jr, A. O., Lan, W. Y., Tallent-runnels, M. K., Stevens, T., Tallent-runnels, M. K., \& Olivarez, A. (2016). Role of Mathematics Self-Efficacy and Motivation in Mathematics Performance Across Ethnicity. 97(4), 208-221.

Toland, M. D., \& Usher, E. L. (2016). Assessing Mathematics Self-Efficacy: How Many Categories Do We Really. Journal of Early Adolescence, 36(7), 932-960. https://doi.org/10.1177/0272431615588952

Yusuf, M. (2011). The impact of self-efficacy, achievement motivation, and self-regulated learning strategies on students' academic achievement. Procedia - Social and Behavioral Sciences, 15, 2623-2626. https://doi.org/10.1016/j.sbspro.2011.04.158

Zimmerman, B. J., \& Bandura, A. (1994). Impact of Self-Regulatory Influence on Writing Course Attainment. American Educational Research Journal, 31(4), 845-862. https://doi.org/10.3102/00028312031004845 